\title{
Outcomes of Sustainable Practices: A Triple Bottom Line Approach to Evaluating Sustainable Performance of Manufacturing Firms in a Developing Nation in South Asia
}

\author{
S. Sapukotanage ${ }^{1}$, B.N.F. Warnakulasuriya ${ }^{2}$, S.T.W.S. Yapa ${ }^{2}$ \\ ${ }^{1}$ The Open University of Sri Lanka, Sri Lanka \\ ${ }^{2}$ University of Sri Jayawardenapura, Sri Lanka \\ Correspondence: S. Sapukotanage, The Open University of Sri Lanka, Sri Lanka
}

Received: October 26, 2018

Accepted: November 27, 2018

Online Published: November 29, 2018

doi:10.5539/ibr.v11n12p89

URL: https://doi.org/10.5539/ibr.v11n12p89

\begin{abstract}
Maintaining sustainable operations has become a major responsibility of practitioners. Sustainable practices are executed to ensure sustainable performance. Many studies conducted to examine the outcomes of sustainable practices have focused either on the economic outcomes, social outcomes or environmental outcomes of such operations disregarding the Triple Bottom Line Approach to evaluating sustainable performance. Among them the majority have focused on environmental outcomes. Less focus is placed on developing countries or countries in South Asia. Against this background this paper aims to examine the outcomes of sustainable practices towards sustainable performance of manufacturing firms in a developing nation in South Asia. A study was conducted among 154 apparel manufacturing and exporting firms of Sri Lanka in relation to their sustainable practices and sustainable performance as members of supply chains. The sustainable practices were studied in relation to orientation, collaboration, continuity, risk management and pro-activity while sustainable performance was analyzed along economic performance, social performance and environmental performance of these firms. The findings were analyzed using Variance Based Structural Equation Modelling (Partial Least Squares) and it revealed that sustainable practices lead to sustainable performance even in the context of a developing nation in South Asia, highlighting the importance of the execution of sustainable practices irrespective of the level of development of a nation.
\end{abstract}

Keywords: sustainable practices, sustainable performance, triple bottom line

\section{Introduction}

Organizations are now held responsible for their environmental and social performance apart from their economic performance. As a result, pressures from stakeholders towards maintaining sustainable operations have increased. Sustainability concerns of an organization are not limited to the boundaries of individual organizations but they are held responsible also for the members of supply chains whom they deal with. For example, as a result of poor environmental performance at any stage of the supply chain process may damage what is considered as a firm's premier asset its reputation. With this a strategic approach to supply chain management based on operational sustainability has been developed (Schaltegger and Burritt,2014).

The Triple bottom line approach is a popular framework used for evaluating sustainability of supply chains where not only financial aspects are considered. It emphasizes on the environmental and social measures too. It makes an organization understand that sustainability, at a broader level consists of three components, the natural environment, society and economic performance (Carter and Rogers, 2008). Many authors show a similar understanding of sustainability in relation to an organization. For instance, The 'triple bottom line' was a concept developed by Elkington (1998). It recognizes the integration of environmental, social and economic performance as the three pillars of sustainability and sustainable supply chains.

There is no universal standard method for calculating sustainable performance based on the Triple Bottom Line approach. It allows a user to adapt the general framework to the needs of different entities. The idea behind the 3BL paradigm is that a corporation's ultimate success or wealth can and should be measured not just by the traditional financial bottom lines, but also by its social, ethical and environmental performance. According to the triple bottom line approach an organization can perform a combination of social, environmental and economic activities which 
results in competitive advantage for the firm. The term 'intersection' has a broad meaning here. It identifies the need for a proper combination of strategies for sustainable performance. What is implied from this is that a sustainable performance cannot be expected merely by the practice of economic, social and environmental measures in isolation. The proper 'combination' of all three is necessary. The environmental or social practices carried out for sustainability may raise economic costs. At the same time cutting down costs can result in negative environmental and social outcomes. Literature review cites the empirical evidence on accepted practices and their dimensions in order to move towards sustainability. They are called the sustainable practices. Sustainable practices are expected to lead to sustainable performance (Rao and Holt, 2005, Winter and Knemeyer, 2012, Moretto et.al., 2012, Cater and Rogers,2008, Schaltegger and Burritt,2014 ). But if these practices are not executed in proper combination it may not finally result in sustainable performance. Therefore it is essential that individual organizations identify whether their sustainable practices lead to sustainable performance. This necessitates the conduct of empirical studies to examine the prevalence of this relationship in different contexts.

Brito et.al., (2008) stressed that it is challenging to find consistency in supply chain practices at global level since there seem to be regional differences on the view of Corporate responsibility and sustainability namely between Europe and Asia. It highlights the importance of conducting studies in the domain of sustainable supply chain management in the Asian region. The relationships between sustainable supply chain practices and sustainable performance that have already been identified in literature have not focused on the developing countries. Rao and Holt (2005) highlighting a gap in literature, explain that future research should empirically test such relationships in different countries, in order to have comparative studies. The present study will provide empirical evidence on the sustainable practices adopted and the levels of sustainable performance of manufacturing firms in developing countries, taking Sri Lanka as a case.

Identifying the relationship between sustainable supply chain practices and sustainable performance of apparel manufacturing and exporting organizations of Sri Lanka a gap in literature was addressed.

This paper will be structured as follows: First the literature related to the study will be discussed. Next, the methodology adopted will be explained. It is followed by an explanation of the findings. The conclusion and discussion will be presented next. Finally the managerial implications of the findings are highlighted.

\section{Literature Review}

\section{Sustainable Performance of Manufacturing Firms in a Supply Chain}

Sustainable performance of an organization is explained in literature, as the improvement in its performance in terms of environmental contribution and social contribution while gaining an economic advantage. Therefore, if a firm's performance is to be considered sustainable it should create minimum harm to the natural environment, should meet social needs while achieving its financial goals. Although the three aspects of sustainability have been discussed separately in supply chain management, the triple bottom line approach suggested by Elkington (1998), explained the need to consider them simultaneously. Simultaneous consideration of the three bottom lines of an organization clearly explains the application of the stakeholder theory in its operations. It implies that addressing the interests of all stakeholder groups are equally important for sustainable performance.

Only if performance is measured along these lines can the stakeholder requirements be satisfied. As explained earlier when organizational performance is assessed against the expectations of a variety of stakeholder groups, more attention needs to be paid to the impact of organization's activities on the natural environment and the society while assessing their economic implications. Unless the environmental and social management are linked to the economic success an overall picture of sustainable performance of the firm cannot be obtained since environmental and social scarcities are only partially reflected in economic transactions. As a result, the economic contribution of environmental and social management will remain unclear. Therefore, unless a holistic figure is not calculated a clear picture of sustainable performance cannot be derived. The reason is that there is empirical evidence to justify that inherent connections among economic performance, environmental performance, and social performance is positive (Cruz, 2009; Walsh \& Margolis, 2003).

Therefore, it has become important to measure sustainable performance as a composite figure. Only one recently published article of Hollos et al. (2012) has addressed the triple bottom line concept in the calculation of sustainable performance. The performance that has been identified as sustainable in literature was confined mainly to environmental performance in empirical studies. However, a few conceptual papers have discussed about what really amounts to sustainable performance. The following sections explain how the different dimensions of sustainable performance have been identified in literature.

Overall the impact of an organization's activities on air, water and energy are identified to reflect its environmental 
performance. Social performance is measured in terms of the impact of an organization's activities on the communities. Economic performance of an organization is its financial achievement. Hubbard (2009) identifies that the economic performance can be measured by its profit growth, return on equity, return on assets and gearing (Schaltegger and Burritt, 2014; Hubbard, 2009 ; Verdecho et al., 2012; Sloan, 2010).

\section{Sustainable Practices of a Manufacturing Firm in Supply Chains}

In the context of sustainable supply chains, the initiatives of individual firms aimed at establishing sustainability can be termed as the 'sustainability practices'. The paradigm of sustainable supply chain management has led to the discussion as to what kind of a procedure a company should conduct to integrate the sustainability with its operations in supply chain management. In the words of Warhurst (2002) sustainability practices explain the extent of social responsibility integrated in some way to give a means of measuring progress towards or away from sustainability. It identifies that the sustainable practices include those practices that are expected to bring about positive outcomes environmentally, socially as well as economically. According to Schaltegger and Burritt (2014) sustainable practices involve consideration of environmental factors and social aspects of organizational activities as well as their integration with conventional economic performance. The important fact stressed in these explanations is the need for a combination of social, environmental and economic initiatives. Research on environmental aspects of sustainability has been given more importance in many research studies while less attention has been given to social aspects of performance and how different aspects of performance are related to each other (Lehtonen, 2004). The reality is that organizations pay more attention on achieving economic objectives to remain profitable in the marketplace. It results in social welfare being viewed as a secondary goal. At the same time some authors argue that attempts to maintain a balance among the three pillars of sustainability performance can be a costly exercise. Therefore, although all the three bottom lines of an organization have been addressed for sustainability there may be differences in the application. Pagell and $\mathrm{Wu}(2009)$ explain that the managerial practices adopted by many sustainable chains are those that are linked to enhanced organizational performance. Some of the novel practices they have highlighted are traceability (information sharing), focus on sourcing and investing in employees indicating a trend towards social practices. What is important to be understood is the fact that synergistic effects exist where improved performance in one area corresponds to higher performance in other areas and that it is an incentive for companies to engage in sustainability practices (Janzzen et al., 2015). For an example, refraining from toxic dyes in textile manufacturing can reduce environmental impacts, improve the health conditions for workers and customers and reduce costs of production, leading to environmental, social and economic benefits at the same time.

Among many definitions of sustainability initiatives that have been discussed in relation to the processes of a supply chain the ones that So et al. (2012) identified in relation to the Supply Chain Operations Reference (SCOR) model are straightforward. They emphasize the initiatives for sustainability that could be identified with the five primary SCM processes: i.e. Plan, Source, Make, Deliver, and Return, in association with new operational activities like green purchasing (Source), clean production (Make), green logistics (Delivery) and reverse logistics (Return).

Mejias and Pardo (2013) refer to sustainable practices as enormous effort of companies to reconfigure the existing practices and strategic thinking and to adapt to radical sustainable innovations across the supply chain.

Researcher found it reasonable to categorize the sustainable practices discussed in literature under the five broad headings (umbrella terms) identified by Beske and Seuring (2014). They identify these five broad headings as 'categories'. They are orientation, continuity, collaboration, risk management and pro activity directed at sustainability of organizations. This classification has been done taking into consideration the relationship of each practice to the strategy of an organization, its structure and the processes involved. The sustainable practices that are linked to the strategic level of an organization are the orientation towards the triple bottom line and the supply chain management. These are listed under the broad category of 'orientation'. The structure related practices are categorized as 'continuity'. They involve long term relationships, supply chain partner selection and partner development. Risk management and pro-activity are the categories of sustainable practices related to the processes of an organization. Selective monitoring, standards and certification and pressure groups are the practices related to risk management. Learning, stakeholder management, innovation and life cycle assessment are identified as pro-activity related practices of sustainability. Collaboration is related both to the structure as well as to the processes. Technological integration, logistical integration, enhanced communication and joint development are the practices related to collaboration.

The list of practices in the framework of Beske and Seuring (2014) include almost all the practices identified in previous literature providing a clearer classification of dimensions along which these practices could be identified. It provided the present study a clear framework for conceptualizing the sustainable practices. Therefore, the present study used the above framework of Beske and Seuring (2014) to analyze the sustainable practices 
identified by several other authors. Methodologically too, there is a valid reason why this framework is suitable. This classification has been done in relation to the strategy of an organization, its structure and the processes involved. It enables the application of objectivity since the researcher emphasizes the formal properties of organizations and views it to be comprised of processes and structures.

\section{The Relationship between the Application of Sustainable Supply Chain Practices and Sustainable Performance of Individual Organizations}

There are those who argue that the implementation of environmental or social initiatives can result in substantial losses. The implication is that sustainable performance is negatively influenced by implementing initiatives to protect the environment and the society since they may involve costs that lead to poor economic performance. But many of the literature reviewed addressed the positive side of it where sustainable performance is positively influenced by the implementation of sustainable supply chain initiatives. Carter and Rogers (2008) explained that organizations that focus on all the three bottom lines can achieve higher economic performance than those that emphasize only on one or two of the three components of the triple bottom line. Moretto et al. (2012) stated that through sustainable practices Italian fashion industry could improve innovation performance in terms of sustainability. Organizations engaged in environmental protection and operating with an understanding of their social responsibility have been found to be gaining long-term benefits (Brammer\& Millington, 2008). At the same time, it is argued in literature how higher economic benefits empower corporations to take greater social responsibility. Those who are economically strong can spend more money on pollution treatment, provide more benefits for society, and improve the welfare of their employees (Cao \& Zhang, 2011; Li et al., 2014).

In explaining the positive relationship between sustainable practices and sustainable performance, in most of the researches performance is calculated only in relation to environmental performance (where sustainable performance is treated equivalent to environmental performance). Rao and Holt (2005) explained that greening the different phases of the supply chain leads to an integrated green supply chain, which ultimately leads to competitiveness and economic performance. They have explained that green supply chain management promotes efficiency and synergy among business partners and their lead corporations, and helps to enhance environmental performance, minimize waste and achieve cost savings. They also explain that environmental management encompasses diverse initiatives to reduce or minimize the adverse environmental impacts of an organization's operations and they improve environmental performance, reduce costs, enhance corporate image, reduce risks of non-compliance and further strengthen marketing advantages. Economic gains could be achieved in two ways by complying with environmental and social standards (Glocic and Smith, 2013). One is by way of cumulative cost savings available from decreased natural resource consumption or lower waste levels. (Lankoski,2009). The other is by way of cost reduction (Pullman et al., 2009). Carter (2005) explains cost reduction to include total production, labour, material and service costs. Positive effects of sustainable procurement on cost reduction could be identified with methods such as life cycle assessment. When production is carried out under strict ecological and social standards the number of process interruptions are less. Enhancement of throughput resulting from reduced interruptions reduce unit costs of production. This is an advantage of sustainable products (Brady et al.,1999). These authors further explain that the same amount of output can be achieved with fewer or the same level of resources than traditional methods with the concept of eco efficiency. This results in reduced cost per purchased item. Less energy consumption, possibilities of refilling and restoration, having a longer life span and elimination of pollution and associated legal problems or penalties are other noticeable gains from sustainable products. In occasions where there are restrictions on disposal methods to avoid any harm to the environment, having sustainable products will reduce disposal expenses. In addition, the financial resources obtained from waste prevention can be reinvested in the company to provide employees with advanced equipment. These explanations show how green practices positively influence cost reduction. Similar impact on cost could be gained from social practices too. Social practices may involve providing superior wages and conducive working conditions, Cost reduction through social practices happens as a result of reducing the costs involved in breakdowns, poor safety standards and higher employee absenteeism (or even the costs of compensation for work related accidents or diseases will go down when social and safety standards improve) .Motivated work force happens to be a productive workforce too, when working conditions improve. It reduces the material cost. The motivated work force will amount to increased process innovation. Innovative behavior of employees creates greater organizational support for product quality, reduces lead time and improves supply security. Existence of balanced working hours and sufficient breaks improves workers' attention to their tasks. It will reduce manufacturing errors and will ultimately result in enhanced quality of products. When the employees get sufficient leisure time between shifts it also lowers the amount of defective parts being produced and thereby reduces material costs. With the reduction in the need for subsequent processing of defective material, labour costs can be brought down. 


\section{Methodology}

The research strategy of the present study was quantitative. The quantitative design involved elaborating theory, devising hypotheses, selecting a research design, devising measures of concepts, selecting research subjects, administering research instruments and collecting data, processing the collected data and analyzing them using quantitative techniques (Bryman and Bell,2008). In devising the measures of concepts researcher tested and validated the research model, thereby to establish theory for better understanding and predicting the relationship between sustainable supply chain practices and sustainable performance (Sekaran and Bougie, 2012).

The theoretical understanding in this study was that the sustainable performance of a manufacturing firm results from sustainable supply chain practices.

Accordingly, two main constructs; sustainable supply chain practices \& sustainable performance were identified in the conceptual domain of the study. Each of these constructs were multidimensional. Sustainable supply chain practices consisted of five dimensions; orientation, continuity, collaboration, risk management and pro-activity (Beske and Seuring, 2014). Sustainable performance had three dimensions; economic performance, social performance and environmental performance (Hubbard 2009).

In analyzing the relationships mentioned above two descriptive hypotheses and a relational hypothesis were developed in this study.

H1: The level of sustainable performance is high among individual firms in the apparel manufacturing and exporting industry of Sri Lanka.

H2: The level of application of sustainable supply chain practices is high among individual firms in the apparel manufacturing and exporting industry of Sri Lanka.

H3: The higher the level of application of sustainable supply chain practices, the higher the level of sustainable performance of individual firms in the apparel manufacturing and exporting industry of Sri Lanka.

\section{The Conceptual Model}

A conceptual model shown in Figure 1 was developed by the researcher mainly based on the argument that when an individual member of a supply chain adopts sustainable supply chain practices they can move towards better sustainable performance.

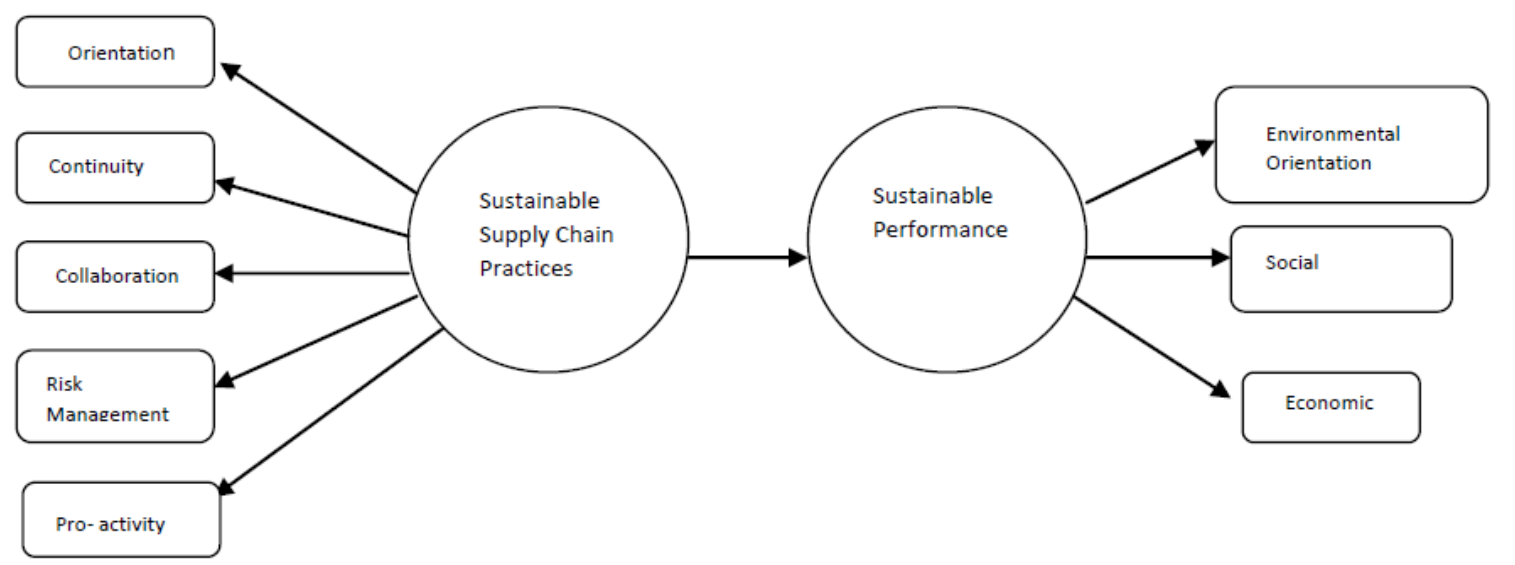

Figure 1. The Conceptual Model of the Study

Sustainable supply chain practices have been discussed in many research studies before. However Beske and Seuring (2014) provided a sound classification of dimensions of the construct. It enabled the researcher to identify sustainable supply chain practices as a multidimensional construct having indicators for each dimension. Law et al. (1998) explained the advantages of having a multidimensional construct. According to them that the dimensions of a multidimensional construct can be conceptualized under an overall abstraction and using the overall abstraction as a representation of the dimensions is theoretically meaningful and parsimonious. Due to this reason, the researcher considered sustainable supply chain practices as a multidimensional construct consisting of the dimensions identified by Beske and Seuring (2014). The sustainable performance of individual organizations also has not been studied as a composite concept in previous studies. Rather, only the individual dimensions of sustainable performance have been taken to reflect sustainable performance rather than taking it as a combination of environmental, social and economic performance. This highlights that the application of the 
Triple Bottom Line approach is not evident in the previous studies in conceptualizing sustainable performance. In the present study sustainable performance was treated as a multidimensional construct consisting of environmental, economic as well as social performance.

Multidimensional nature of the constructs caused both first order constructs and second order constructs to be present in the model. The first order constructs were the dimensions of sustainable supply chain practices (orientation, continuity, collaboration, risk management and pro-activity) and dimensions of sustainable performance (environmental, social and economic). The second order constructs were sustainable supply chain practices and sustainable performance. Indicators were identified for the first order constructs.

In this present study the interest of the researcher was to investigate into the relationship between sustainable supply chain practices and sustainable performance of individual firms in the apparel manufacturing and exporting industry of Sri Lanka. Therefore, the unit of analysis was the organization. The focal entity under analysis was the manufacturer since it had been taken as the main entity of analysis in majority of supply chain management related research (Chen and Paulraj, 2004). 'Manufacturer' was identified as an entity that provided a final finished product to anyone of 'distributor', 'retailer', 'logistics provider' or 'consumer'. The reason behind the selection of the apparel manufacturing and exporting industry to represent the sample was that the organizations in this industry operate in the global network where sustainability is a major requirement for survival.

In the analytical domain the constructs had to be translated into measurable variables because these constructs could not be observed and they could only be studied through the indicators that were developed to measure them. Indicators that captured the domain of the constructs were identified through a thorough literature review. Accordingly, there were 05 indicators to measure orientation, 11 indicators to measure continuity, 05 indicators to measure collaboration, 08 indicators to measure risk management and 24 indicators to measure pro-activity. Environmental performance was identified to be having 06 indicators while social performance and economic performance were identified to be having 07 indicators and 11 indicators respectively.

Researcher developed a questionnaire to enable data collection using measurable indicators identified through the literature review. Questions were designed in such a manner that the indicators of all the first order constructs (dimensions) were presented in the form of questions. Participants were asked to respond to the questions related to sustainable supply chain practices using a 5-point Likert scale where 1 denoted 'Strongly agree', 2 denoted 'Agree', 3 denoted 'Neither agree nor disagree', 4 denoted 'Disagree' and 5 denoted 'Strongly disagree'. This scale was expected to pave the way for the calculation of values for sustainable supply chain practices. Questions that were asked to measure the sustainable performance was a benchmarking exercise where the respondent firms were required to place their organizations on a 5 point Likert scale where 1 denoted 'Strong positive variations', 2 denoted 'Weak positive variations', 3 denoted 'No variations', 4 denoted 'Weak negative variations' and 5 denoted 'Strong negative variations' This scale was intended to make it possible for the calculation of performance values for each dimension of sustainable performance separately and also an aggregate value for sustainable performance (economic performance, social performance and environmental performance). Here the researcher expected the respondent firms to state their level of performance considering industry average as a benchmark.

A pilot test was carried out to collect data to validate and refine the questionnaire before it was administered in the main survey. The pilot testing of the questionnaire was carried out with 35 managers representing apparel manufacturing and exporting firms of Sri Lanka. Through this test of the questionnaire for its psychometric properties, with 35 respondents, validity and reliability of the measurement items were established. At the end of this exercise 30 out of the 53 items that were expected to measure sustainable supply chain practices and 11 out of the 24 items that were expected to measure sustainable performance were found to be reliable and valid. The questionnaire so refined was used in the main study for data collection. Data was collected from 154 respondents. The sample consisted of 109 large, 40 medium and 05 small apparel manufacturing and exporting organizations of Sri Lanka.

Once the data was collected the researcher used both univariate and multivariate techniques to establish the normality of the data set. The psychometric properties of the measures of the constructs was also examined by performing the Confirmatory Factor Analysis (CFA) which is an inherent application of PLS.

The values of the outer loadings of the measurement model representing the estimates for the relationships between the reflective first order latent constructs and their indicators established the unidimensionality of the measures. Having confirmed the unidimensionality, internal consistency and the validity of the measures were assessed. HTMT criteria (Kline, 2011) were used to check for their discriminant validity. This exercise was carried out at first order level as well as second order level (Hair et al., 2014). The values obtained for the factor loadings, Cronbach Alpha values, Composite reliability and Average Variance Extracted matched the threshold 
values as shown in Table 1 . The HTMT ratio below 0.85 also was in support of the discriminant validity of the first order constructs.

As the research involved exploring relationships at a higher level of abstraction, each second order construct (sustainable supply chain practices and sustainable performance) was assessed for their psychometric properties.

Table 1. Factor loadings, Cronbach Alpha values, Composite reliability and Average Variance Extracted of First Order Constructs

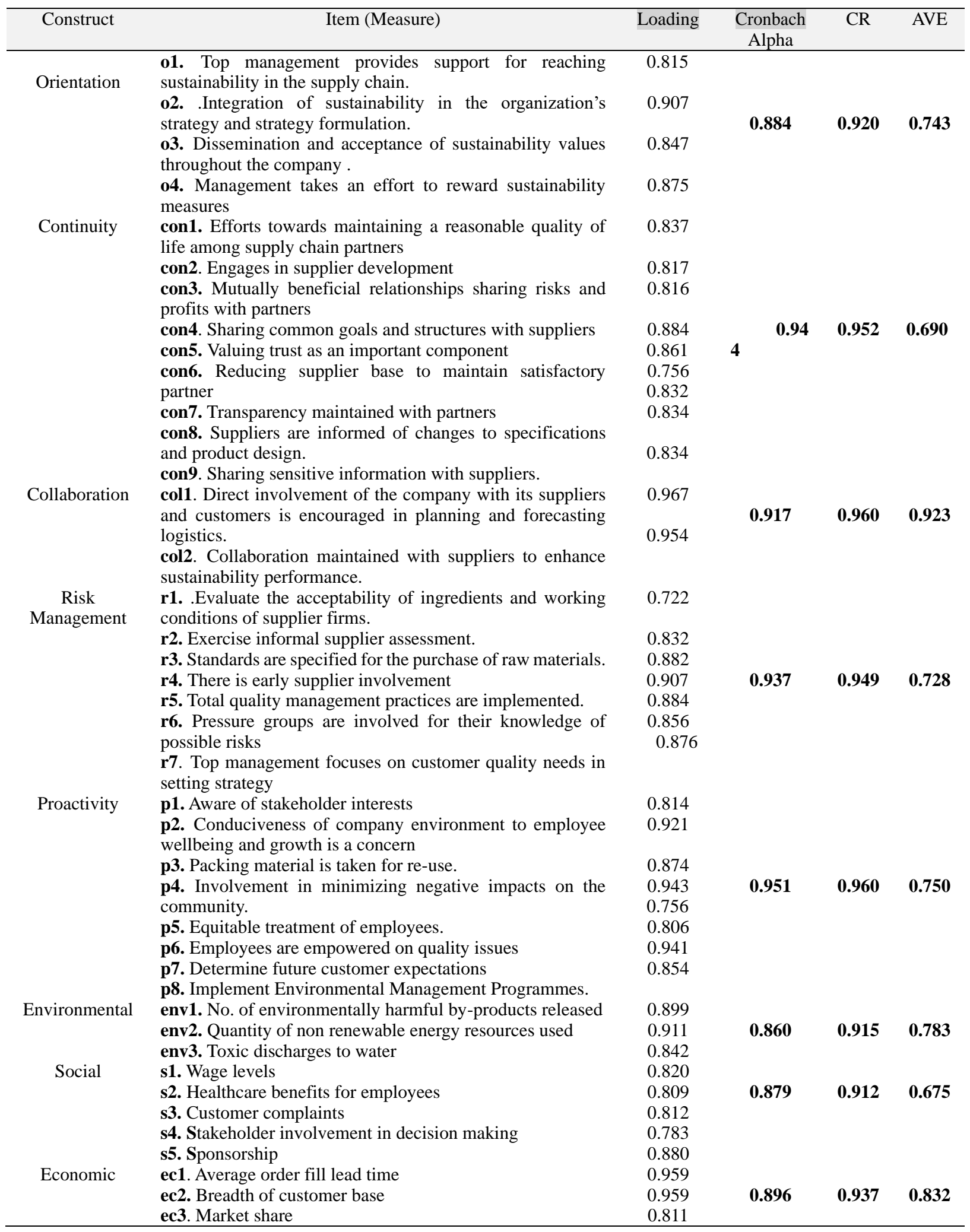


The results in Table 2 show the Cronbach Alpha value which established the internal consistency and the values of composite reliability \& Average Variance Extracted of the second order model which were above the threshold values providing evidence of convergent validity of higher order constructs too.

Table 2. Psychometric Properties (Internal Consistency and Validity) for Second Order Constructs

\begin{tabular}{llcc}
\hline & $\begin{array}{l}\text { Cronbach's } \\
\text { Alpha }\end{array}$ & $\begin{array}{l}\text { Composite } \\
\text { Reliability }\end{array}$ & $\begin{array}{l}\text { Average } \\
\text { Variance } \\
\text { Extracted } \\
\text { (AVE) }\end{array}$ \\
\hline SUSP & & 0.911 & 0.925 \\
SUSPRAC & & 0.972 & 0.529 \\
\hline
\end{tabular}

\section{Findings}

The structural model was assessed to understand the relationship between the second order constructs which provided the main finding of the study. The results revealed that the path coefficient from sustainable supply chain practices to sustainable performance was 0.820 . The significance of these values was established through a bootstrapping procedure which revealed that the coefficient was significant since it was well above the threshold value of 1.96. This finding is consistent with the underlying theory and conceptualization of the original model. The original model hypothesized that sustainable supply chain practices contributed positively towards sustainable performance. The result of the model setup with the data collected from the apparel manufacturing and exporting industry of Sri Lanka provided empirical evidence that sustainable supply chain practices contribute positively and significantly to strengthen sustainable performance.

The $\mathrm{R}^{2}$ value 0.824 of the endogenous variable, i.e. sustainable performance provides adequate evidence for the predictive accuracy of the model. The model was developed with the data collected from the apparel manufacturing and exporting industry of Sri Lanka. Therefore, it's reasonable to assume that sustainable supply chain practices can explain $82 \%$ of a firm's sustainable performance in the apparel manufacturing and exporting industry of Sri Lanka. The results revealed a $f^{2}$ value of 1.718 . The Stone Geisser's $\mathrm{Q}^{2}$ value indicating the predictive relevance of the model was 0.405 . These values confirm the relevance of the model to explain the relationship between sustainable supply chain practices and sustainable performance.

The present study also revealed that the items identified as measures (indicators) of the categories (dimensions) of sustainable supply chain practices identified by Beske and Seuring (2014) were true reflectors of those categories. It established that they are suitable to be considered as first order constructs.. The aim of this exercise was to enhance parsimony of the model.

In the present study the researcher identified sustainable performance as a second order construct while taking environmental, social and economic performance as first order constructs to include all indicators of sustainable performance in calculating the sustainable performance of apparel manufacturing and exporting organizations of Sri Lanka. These three first order constructs, proved to be well reflective of sustainable performance giving a composite estimate for sustainable performance.

Through these exercises the present study could develop a sound measurement model with higher order constructs to establish parsimony. The hypothesis that the level of sustainable performance is high among individual firms in the said industry was proved through the one sample t-test. The second hypothesis that the level of application of sustainable supply chain practices is high among individual firms in the said industry was also proved through the One sample t-test. In testing the third hypothesis PLS-SEM, a multivariate analysis technique was used. The path coefficient in the structural model from sustainable supply chain practices to sustainable performance of 0.820 was in proof of this hypothesis. The t-statistic for this coefficient was 20.001 proving the significance of the relationship.

\section{Conclusion and Discussion}

\subsection{Conclusion}

The results of the present study showed that greater the sustainable supply chain practices adopted the greater was sustainable performance. They met the objectives set out at the beginning of the research, which were to:

- Examine the level of sustainable performance of individual firms in the apparel manufacturing and exporting industry of Sri Lanka where sustainable performance is inclusive of all pillars of the triple bottom line

- Identify how sustainable supply chain practices are adopted by individual firms in the apparel manufacturing and exporting industry of Sri Lanka and 
- Examine the relationship between sustainable supply chain practices and sustainable performance of individual organizations in the apparel manufacturing and exporting industry of Sri Lanka

The results of the one sample t-test showed that sustainable performance of the apparel manufacturing and exporting firms of Sri Lanka remains at a higher level. While achieving the objective of examining the level of sustainable performance of individual firms in the apparel manufacturing and exporting industry of Sri Lanka, the research addressed two existing gaps in literature. One was by identifying the level of sustainable performance of manufacturers in a developing country in Asia. The second was by determining sustainable performance based on all three pillars in measuring sustainable performance.

The results demonstrated that there is a high level of adoption of sustainable supply chain practices in the apparel manufacturing and exporting industry of Sri Lanka. While achieving the objective of identifying how sustainable supply chain practices are adopted by individual firms in the apparel manufacturing and exporting industry of Sri Lanka researcher addressed two existing gaps in literature. One was by way of identifying the sustainable practices in a developing country in Asia. Second, was by way of validating the measures of sustainable supply chain practices at a higher level of abstraction.

The PLS analysis showed that in the apparel manufacturing and exporting industry of Sri Lanka sustainable supply chain practices lead to sustainable performance. This finding adds to the sustainable supply chain management literature a new finding in relation to a developing country in Asia which has not been studied before. The results complement a number of recently published studies in the developed nations in the Western world and extend the research into new areas.

\subsection{Discussion}

\section{The Level of Sustainable Performance of Individual Firms in the Apparel Manufacturing and Exporting} Industry of Sri Lanka.

Since sustainable performance has become a major determinant of the competitive advantage of apparel exporting firms in the global apparel industry, it is not surprising to see the firms maintain high levels of sustainable performance. As far as the performance in relation to the three different pillars was concerned, the emphasis on social performance of the apparel exporting firms of Sri Lanka was relatively higher than on the other two pillars. This was quite different from the explanation of Seuring (2011) which says that across a range of studies it was observed that environmental and social standards serve as minimum requirements which have to be fulfilled to stay in the market while orders are won against economic performance, i.e. product-and delivery-related criteria, measured in conventional terms such as quality, speed and dependability of deliveries, flexibility in volume and product changes and resulting costs. Researcher prefers to attribute this difference in the composition of sustainable performance in the apparel manufacturing and exporting industry of Sri Lanka from that of the literature (more emphasis on social performance), to the cultural and ethical aspects in the contextof sustainability in supply chain management as referred to in the Editorial of the Journal of Cleaner Production (2008).

In many research studies sustainable performance is attributed to environmental performance. However, sustainability not only includes environmental performance, but also the social as well as economic performance of the manufacturer. The sustainable performance of an organization needs to be judged from its ability to earn economic returns while protecting the natural environment and the society at large. The importance of multi-dimensional assessment frameworks in coping with stakeholder pressure has been identified by Varsei et al. (2014). According to the explanation of Figgie et al. (2002) economic transactions do not reflect a total picture of environmental and social scarcities.But the sustainable performance of any organization involves not only economic performance but also social performance. As a result, measuring sustainable performance only in terms of economic performance does not provide a clear picture of an organization's sustainable performance. This creates a need for a multi-dimensional framework to measure sustainable performance. This view has been further established by Hanifan et al. (2012) when they say that companies will need to look into ways of reflecting the results of sustainable practices in assessing the total cost of an economic activity. This is the Triple Bottom Line approach in measuring sustainable performance introduced by Elkington in the year 1998. The argument presented by the supporters of the Triple Bottom Line approach (TBL) is that overall fulfillment of objectives to stakeholders should be measured, calculated, audited and reported (Norman and Mc Donald, 2003; Seuring and Muller, 2008; Varsei et al., 2014; Reefke and Trocchi, 2013; Svensson, 2007). They believe that, if ethical business practices and social responsibility are important functions of corporate governance and management, then tools need to be developed to make it transparent tomanagers, shareholders and other stakeholders how well it is performing in that regard. In the words of these supporters the TBL approach defines a company's ultimate worth in financial, social 
and environmental terms. This view of addressing the additional bottom lines is supported with a measurement claim, whereby they say that TBL approach is easy to apply since objective measures are available to quantify social and environmental performance. At the same time there are those who argue that social performance and environmental performance cannot be quantified. The argument is that although measures of financial performance provides a net result after deducting the expenses from the revenue, the measurement of social and environmental performance does not enable such calculation. However, still they admit the fact that these two bottom lines of performance can be quantified thus making it possible to incorporate them in the calculation of sustainable performance. At the same time, the need for appropriate mechanisms to suit the type of performance has been raised in literature (Norman and Mc Donald, 2003), mainly in relation to social performance. An alternative mechanism that is used in the measurement of social and environmental performance is where one firm's social performance is compared against the other organizations in the industry, through a benchmarking exercise. The criticisms against the TBL approach to identifying sustainable performance as an aggregate measure have been addressed through this exercise (Hubbard,2009; Varsei et al., 2014; Norman and Mc Donald, 2003). The present study adopted this benchmarking exercise to obtain responses for sustainable performance. The perceptual evaluation of the respondents on their own performance was rated based on a comparison of the firm's performance against industry average, as the benchmarking exercise. If a firm perceived that it performed very much better than this average they rated themselves as 'strong positive variations' with a score of ' 1 ' on the Likert scale. If they perceived their performance to be better than the industry average but not very much ahead then they rated themselves as 'weak positive variations' with a score of ' 2 ' on the Likert scale. If they found their performance in par with other competitors, they rated themselves as 'no variations' with a score of ' 3 ' on the Likert scale. If the performance was found to be below average, then the rating was for 'weak negative variations' or 'strong negative variations' with scores of ' 4 ' or ' 5 ' on the Likert scale respectively.

The TBL approach is appreciated for the transparency it provides in reporting the information about performance. Pava (2007) states that TBL approach is a step in the right direction putting the notion of accountability back into accounting. The author identifies that it is derived from a more ethically defensible theory of the firm than traditional annual report which solely emphasizes on profit maximization for shareholders. Therefore, the TBL could be justified as a proper approach for the calculation of sustainable performance and the present study believed the use of TBL is important irrespective of the criticisms against it. The performance related to all three dimensions of sustainable performance, i.e. environmental performance, social performance and economic performance were therefore considered as the dimensions in arriving at an aggregate value for sustainable performance of apparel manufacturing and exporting organizations of Sri Lanka.

However, there is a very poor level of acceptance of the claim that sustainable performance can be identified as an aggregate figure of the performance in the three bottom lines. The reason for the lack of availability of a composite measure of sustainable performance in literature may be the reason for lack of support for the aggregate claim of the TBL, by many researchers. Although Gimenez et al. (2012) identify sustainable performance in terms of the three bottom lines they have not arrived at an aggregate measure. Therefore, one of the objectives of the research was to address this gap in literature. In the present study an avenue through the methodology was identified to incorporate all the three pillars in the measurement of sustainable performance. Sustainable performance was considered as a higher order factor. The individual three pillars of performance were considered as dimensions of sustainable performance to be represented by first order factors. This enabled the calculation of an aggregate measure for sustainable performance in the structural model.

Out of the 24 items that were identified from the literature review to measure sustainable performance using all three pillars of the triple bottom line only 11 were identified by the apparel manufacturing and exporting industry of Sri Lanka to reflect their own sustainable performance. The measures of environmental and economic performance that they perceived to be not represented by the construct would have been those that were not directly related to their industry because the measures identified from literature were not specific to the apparel industry. The fact that there are possibilities of context specific variations in the measurement items is explained by Clift (2003) when he explains that although general indicator frameworks can be developed, it is commonly agreed that indicators need to be established on a sector-by-sector or even case-by-case basis. This could be clearly seen in relation to the measures of environmental performance. The items that were dropped from the questionnaire such as Carbon Monoxide emissions were not directly related to the apparel industry. Items such as number of accidents is not a measure that is highly relevant to the apparel industry.

However, there were reasons to believe that the practices they selected were not solely based on the industry, but their national culture too may have played a role, as highlighted in the Editorial of the Journal of Cleaner Production (2008). This was reflected in the items that the respondents selected as those that were used in the 
measurement of sustainable performance. Five out of the seven measures of social performance that were stated in literature were identified by the respondents too, as the measures that were used in measuring social performance. Comparatively only 3 out of 6 items and 3 out of 11 items stated in literature were considered by respondents as measures of their own environmental performance and economic performance respectively. This reflects the importance assigned to the responsibility towards the society by the respondents. Thepath model also shows that social performance is the dimension which is explained the most, by sustainable performance (0.749). When the performance statistics for the 154 apparel exporting firms of Sri Lanka were examined carefully in detail, the researcher realized that the respondent firms find them performing better socially when compared to the other dimensions of performance with a mean value of 1.68 . Their perceptual evaluation of the statements show that they agree that their environmental performance was better than economic performance when compared with the industry average. This finding differs from those of many other research studies. As stated above, Seuring (2011) says that across a range of studies it was observed that environmental and social standards serve as minimum requirements which must be fulfilled to stay in the market while orders are won against economic performance. Poor environmental performance of developing countries has also been identified by Nnorom and Osibanjo (2008), in a study on e-waste of developing countries. An Extended Producer Responsibility (EPR) has been suggested through this research, as a remedy to get the manufacturers more involved in environmental performance.

\section{Sustainable Practices Adopted by Individual Firms in the Apparel Manufacturing and Exporting Industry of Sri Lanka}

With the statistics obtained from the quantitative analysis a high level of application of sustainable practices could be observed in the apparel manufacturing and exporting industry of Sri Lanka.

The mean value of the responses for the adoption of sustainable supply chain practices in the apparel exporting industry of Sri Lanka was 1.81. This was an indication of the adoption of sustainable supply chain practices in the apparel exporting industry of Sri Lanka at a considerable level. The descriptive statistics helped in understanding the types of practices adopted and their level of adoption in detail. As discussed in previous chapters, sustainable supply chain practices can be exercised by way of orientation, continuity, collaboration, risk management and proactivity (Beske and Seuring, 2014). This classification of sustainable practices could be identified as addressing the internal measures and external measures of making supply chains sustainable. While orientation, risk management and pro-activity could be recognized as internal measures, continuity and collaboration could be identified as external measures. This showed similarities to the frameworks of supply chain initiatives used by Brito et al. (2008) and Gimenez et al. (2012) in their studies. Their classification of initiatives broadly as internal organization and external organization, provide a clear distinction of the focus of different practices. According to Brito et al. (2008) internal organization is related to the means of achieving product and/or process innovation by using the recent technological development and high skilled labour in the organization's operations to suit sustainability. External organization is related to better management of relationships towards sustainability. The classification of practices by Schaltegger and Burritt (2014) identified the application of sustainable practices along the supply chain in terms of risks and opportunities. According to them this involves practices aimed at eliminating existing and potential problems at production sites and suppliers' vs realizing sustainability driven product designs. The practices addressed through orientation, continuity, collaboration, risk management and pro-activity are similar in nature. Under these dimensions suggested by Beske and Seuring (2014), 53 items were identified to measure sustainable practices. When the apparel exporting firms of Sri Lanka were asked to respond to a questionnaire containing these items there were only 30 items that they considered as representative of sustainable practices, indicating that those were the practices in existence in the apparel manufacturing and exporting industry of Sri Lanka. This poses a reasonable question for the researcher as to whether the sustainability practices have been carried out just in terms of compliance or whether the practitioners are committed towards implementing sustainable practices. Brito et al. (2008) explain that the leaders of sustainable performance are moving beyond sustainability as merely a compliance issue or even an exercise in risk management. Rather they identify opportunities for business improvement through sustainable initiatives. A closer look at the items that were deleted from the questionnaire show that majority of them represent pro-activity related practices which were identified very important by Klassen and Whybark (1999). The proactive measures that are already in practice in the apparel manufacturing and exporting industry of Sri Lanka too, are focused more on the employees and the consumers rather than the products and processes. This also indirectly implies of more of a 'compliance' rather than committed involvement.

Descriptive statistics further showed clearly that the sustainable practices related to continuity and collaboration which involved more interaction with other partners of the supply chain (external organization) are relatively high with mean values of 1.78 and 1.79 respectively. Risk management was also practiced at a considerably higher level 
with a mean value of 1.81 . According to the descriptive statistics proactivity is the next dimension of sustainable practices that the firms have focused more with a mean of 1.80 . However, an important observation regarding the sustainable practices of apparel manufacturing and exporting firms of Sri Lanka was the relatively low importance attached to the orientation towards sustainability. Orientation is important to inculcate a sustainability culture within the organizations. Then only will the practices last for long. However, from the nature of practices that have been adopted it indicates that they have just been focusing more on the structural and operational means of ensuring sustainability than focusing on the strategy. Pagell and Wu (2009) stress the importance of integrating sustainability goals, practices and cognitions into day-to-day supply chain management. They emphasize that the responsibility for sustainability cannot be given to a separate entity within the organization. It must be a part of everyone's job, starting with top management. However, through the interviews conducted with the managers of the apparel exporting firms the researcher could not notice an interest more than an adherence to a legal requirement. An interest in maintaining sustainable operations as an inbuilt philosophy directed at sustainability was not revealed through the interviews. Schaltegger and Burritt (2014) clearly state that sustainability needs to be much more than a box ticking exercise though many companies still appear to believe that simply communicating their carbon management information to the outside world will suffice.

The above said findings of the present study were like that of Moretto et al. (2012) where a stronger attention to supply chain-oriented practices were placed despite product-oriented ones. The national culture also may have influenced the emphasis to be more on relationship-oriented practices, as highlighted in the Editorial of the Journal of Cleaner Production (2008).

Ninety percent ( $90 \%$ ) of the sustainable practices related to external parties, involved interaction with suppliers. This indicated that the manufacturing firms consider the sustainability of their suppliers important. This was a justification for the significance of the present study. The rationale for hypothesizing the relationship between sustainable supply chain practices and sustainable performance as a positive outcome of relational exchanges with suppliers, was also established through this finding.

\section{The Impact of Sustainable Supply Chain Practices on SustainablePerformance of Individual Firms in the Apparel Manufacturing and Exporting Industry of Sri Lanka.}

Although many research studies have understood that sustainable supply chain practices will lead to sustainable performance very less emphasis has been placed on this in Asia. No studies have focused on developing countries. The fact that sustainable supply chain management is challenging due the cultural and political differences in countries with often unstable political and socio- economic conditions has been highlighted by Beske et al. (2008) emphasizing the need to focus on many countries. Therefore, high levels of sustainable practices and sustainable performance cannot always be expected to result in a positive relationship between sustainable practices and sustainable performance as suggested in literature.

In the previous research studies sustainable performance has not been identified as an aggregate measure. Hence the individual dimensions of sustainable practices have been related with those of sustainable performance. Gimenez et al. (2012) explain that internal and external sustainable initiatives bring different results towards the sustainable performance. According to their findings internal measures contribute more towards sustainable performance. Environmental measures were found to improve sustainable performance while social measures were found to be negatively influence sustainable performance. In the present study individual dimensions of sustainable supply chain practices were not related with the individual dimensions of sustainable performance. However, they were related with one another as second order constructs.

This relationship was found to be positive and significant. Within sustainable supply chain practices, the composition of external practices was high. Among the internal practices too the focus on social aspects was high. Therefore, the findings of the present study show no evidence of proof of the negative relationship of social measures towards sustainable performance. This finding is against that of Gimenez et al. (2012).

However, the results of the study conducted by Rao and Holt (2005) provide evidence that support the findings of the present study. They claim that supplier management is also identified important in achieving environmental performance of the manufacturer as well as an improvement in other two bottom lines. Further they explain that many enterprises closely collaborated with their suppliers to fulfill the requirements of the environmental legislations, organize environmental activities such as providing environmental awareness seminars and technical advice to suppliers. These could be identified similar to the practices adopted by apparel manufacturing and exporting organizations of Sri Lanka in relation to their suppliers.

As stated in the social capital theory (Lin ,2002) the relationships help build up cognitive, structural and relational capital which ultimately lead to better outcomes through the relationships. The findings of the present study 
established this logic in relation to the apparel manufacturing and exporting industry of Sri Lanka. One may argue that how could the outcomes of the sustainable practices attributed, to relations with supply chain partners/suppliers? The sustainable supply chain practices show a considerable involvement of suppliers towards sustainable practices. In such a scenario researcher believes it is reasonable to attribute the positive sustainable performance resulting from sustainable supply chain practices, to the relational outcomes of supplier relationships.

The favourable outcomes of successful engagement with their suppliers are identified in literature as, evolving procurement strategies, moving from compliance to performance improvement and building on communication for better decision making. The evolving procurement strategies encourage suppliers to adhere to sustainable practices if they are to continue their contracts with the manufacturers (Seuring and Muller,2008). Apple for example, conducts on-site audits and make sure that suppliers comply with thecode of conduct. In the event of a violation a preventive action plan need to be implemented within 90 days. Moving from compliance to performance improvement the manufacturers can encourage their suppliers to achieve joint benefits by complying with the expected standards. Tata Steel encourages entrepreneurs from disadvantageous communities in India to become suppliers through a combination of local training initiatives and helping with working capital, as well as by giving them preference over larger multinationals provided that certain standards are met. Through building on communication for better decision-making wolmanufacturers can explore new business models. Seuring and Muller (2008) argue that the more the emphasis is placed on supplier development, the more are the win-win situations along supply chain.

\section{Implications of the Study}

The managerial implications of the present study could be identified in relation to sustainable practices. Given the competition in the global apparel industry and the stakeholder demands many companies and practitioners are concerned about gaining a competitive advantage through sustainable operations. This study provides evidence that the firm's level of adoption of sustainable practices will have an impact on its sustainable performance. The research findings show that the individual organizations in the apparel manufacturing and exporting industry of Sri Lanka show a keen interest on adopting sustainable practices in their operations. But these practices are only a few from a long list of practices that were discussed in literature as sustainable supply chain practices. Many items that were identified as pro-active practices were not considered in the main questionnaire since they were dropped at pilot testing. The managers need to be aware and look at the possibilities of adopting such practices in the apparel manufacturing and exporting industry of Sri Lanka since finally the products are offered to the countries in which they are valued and practiced.

The lack of sustainable orientation was a finding that should draw the attention of managers. It is generally understood that good managers create reward systems that link wanted behaviors to outcomes employees' value. The individual employees need to be trained in sustainability (Starik and Rands 1995), and then given incentives to follow through (Daily and Huang 2001). Such linkages provide employees the incentives to pursue sustainability goals along with more traditional goals such as quality improvements. Without these incentives employees are likely to continue pursuing only traditional goals (Handfield et al., 2001).

\section{References}

Beske, J. P., Johnson, M. P., \& Schaltegger, S. (2015). 20 years of performance measurement in sustainable supply chain management - what has been achieved? Supply Chain Management: An International Journal, 20(6), 664-680. Retrieved from https:// www.emeraldinsight.com

Beske, P., \& Seuring, S. (2014). Putting Sustainability into Supply Chain Management. Supply Chain Management: An International Journal, 19(3), 322-331. https://doi.org/10.1108/SCM-12-2013-0432

Brady, K., Henson, P., \& Fava, J. A. (1999). Sustainability, Eco-efficiency, Life-cycle Management, and Business Strategy. Environmental Quality Management, 8(3), 33-41. https://doi.org/10.1002/tqem.3310080305

Brammer, S., \& Millington, A. (2008). Does it pay to be different? An analysis of the relationship between corporate social and financial performance. Strategic Management Journal, 29(12), 1325-1343. https://doi.org/10.1002/smj.714

Brito, M. P., Corinne, C., \& Blanquart, C. M. (2008). Towards a Sustainable Fashion Retail Supply Chain in Europe: Organization and Performance. International Journal of Production Economics, 114(2), 534-553. https://doi.org/10.1016/j.ijpe.2007.06.012

Bryman, A., \& Bell, E. (2012). Business Research Methods. $3^{\text {rd }}$ ed. London: Oxford University Press. 
Cao, M., \& Zhang, Q. (2011). Supply chain collaboration: Impact on collaborative advantage and firm performance. Journal of Operations Management, 29(3), 163-180. https://doi.org/10.1016/j.jom.2010.12.008

Carter, C. R. (2005). Purchasing Social Responsibility and Firm Performance: The Key Mediating Roles of Organizational Learning and Supplier Performance. International Journal of Physical Distribution \& Logistics Management, 35(3), 177-194. https://doi.org/10.1108/09600030510594567

Carter, C. R., \& Rogers, D. S. (2008). A Framework of Supply Chain Management: Moving toward New Theory. International Journal of Physical Distribution and Logistics Management, 38(5), 360-387. https://doi.org/10.1108/09600030810882816

Chen, I. J., \& Paulraj, A. (2004). Towards a Theory of Supply Chain Management: The Constructs and Measurements. Journal of Operations Management, 22, 119-150. https://doi.org/10.1016/j.jom.2003.12.007

Cruz, J. M., \& Matsypura, D. (2009). Supply Chain Networks with Corporate Social Responsibility through Integrated Environmental Decision-making. International Journal of Production Research, 27(3), 621-648. https://doi.org/10.1080/00207540701513901

Daily, B. F., \& Huang, S. C. (2001). Achieving sustainability through attention to human resource factors in environmental management. International Journal of Operations \& Production Management, 21(12), 1539-1552. https://doi.org/10.1108/01443570110410892

Editorial (2008). Sustainability and Supply Chain Management- An Introduction to the Special Issue, Journal of Cleaner Production, 16, 1545-1551. Available from: www.sciencedirect.com

Elkington, J. (1998). Accounting for the Triple Bottom Line. Measuring Business Excellence, 2(3), 18-22. https://doi.org/10.1108/eb025539

Figge, F., Hahn, T., Schaltegger, S., \& Wagner, M. (2002). The sustainability balanced scorecard-linking sustainability management to business strategy. Business Strategy and the Environment, 11(5), 269-284. https://doi.org/10.1002/bse.339

Glocic, S. L., \& Smith, C. D. (2013). A Meta-Analysis of Environmentally Sustainable Supply Chain Management Practices and Firm Performance". Journal of Supply Chain Management, 49(1), 78-87. https://doi.org/10.1111/jscm.12006

Hair (Jr.), J. F., Hult, G. T. M., Ringle, C. M., \& Sardtedt, M. (2014). A Primer on Partial Least Squares Structural Equation Modelling (PLS-SEM), [pdf] USA: SAGE Publications. Retrieved from https://books.google.lk

Handfield, R. B., Melnyk, S. A., Calantone, R. J., \& Curkovic, S. (2001). Integrating environmental concerns into the design process: the gap between theory and practice. IEEE transactions on Engineering Management, 48(2), 189-208. https://doi.org/10.1109/17.922478

Hanifan, G. L., Sharma, A. E., \& Mehta, P. (2012). Why a sustainable supply chain is good business? Outlook, 3, $1-7$.

Hollos, D., Blome, C., \& Foerstl, K. (2012). Does Sustainable Supplier Co-operation Affect Performance? Examining Implications for the Triple Bottom Line", International Journal of Production Research, 50(11), 2968-2986. https://doi.org/10.1080/00207543.2011.582184

Hubbard, G. (2009). Measuring Organizational Performance: Beyond the Triple Bottom Line”. Business Strategy and the Environment, 18, 177-191. https://doi.org/10.1002/bse.564

Klein, R., \& Rai, A. (2009). Interfirm Strategic Information Flows in Logistics Supply Chain Relationships. MIS Quarterly, 33(4), 735-762. https://doi.org/10.2307/20650325

Lankoski, L. (2009). Differential Economic Impacts of Corporate Responsibility Issues. Business and Society, 48(2), 206-224. https://doi.org/10.1177/0007650307306635

Law, K. S., Wong, C. S., \& Mobley, W. H. (1998). Toward a Taxonomy of Multidimensional Constructs. The Academy of Management Review, 23(4), 741-755. https://doi.org/10.5465/amr.1998.1255636

Lehtonen, M. (2004). The environmental-social interface of sustainable development: capabilities, social capital, institutions. Ecological Economics, 49(2), 199-214. https://doi.org/10.1016/j.ecolecon.2004.03.019

Li, Y., Zhao, X., Shi, D., \& Li, X. (2014). Governance of Sustainable Supply Chains in the Fast Fashion Industry. European Management Journal, 32(5), 823-836. https://doi.org/10.1016/j.emj.2014.03.001 
Lin, N. (2002). Social Capital: A Theory of Social Structure and Action, [pdf] New York: Cambridge University Press. Retrieved from https://books.google.lk

Markley, M., \& Davis, L. (2007). Exploring Future Competitive Advantage Through Sustainable Supply Chains. International Journal of Physical Distribution and Logistics Management, 37(9), 763-774. https://doi.org/10.1108/09600030710840859

Mejías, A. M., \& Pardo, J. E. (2013). International Conference on Industrial Engineering and Industrial Management - XVII Congreso de Ingeniería de Organización. pp.59-66

Moretto, A., Laura, M., Caniato, F., Danese, P., Caridi, M., Spina, G., ... Sianesi, A. (2012). Sustainability in the Fashion Supply Industry: An Important Source of Supply Chain Innovation. In: Annual Academic Sessions of Decision Sciences Institute, 75701-755012. Retrieved from http://research.allacademic.com

Norman, W., \& MacDonald, C. (2004). Getting to the bottom of "triple bottom line". Business Ethics Quarterly, 14(2), 243-262. https://doi.org/10.5840/beq200414211

Pagell, M., \& Wu, Z. (2009). Building a More Complete Theory of Sustainable Supply Chain Management Using Case Studies of Exemplars. The Journal of Supply Chain Management, 45(2), 37-56. https://doi.org/10.1111/j.1745-493X.2009.03162.x

Pava, M. L. (2007). A response to "getting to the bottom of "triple bottom line". Business Ethics Quarterly, 17(1), 105-110. https://doi.org/10.5840/beq200717116

Pullman, M. E, Maloni, M. J., \& Carter, C. R. (2009). Food for thought: Social Versus Environmental Sustainability Practices and Performance Outcomes. Journal of Supply Chain Management, 45(4), 38-54. https://doi.org/10.1111/j.1745-493X.2009.03175.x

Rao, P., \& Holt, D. (2005). Do Green Supply Chains Lead to Competitiveness and Economic Performance? International Journal of Operations and Production Management, 25(9), 898-916. https://doi.org/10.1108/01443570510613956

Reefke, H., \& Trocchi, M. (2013). Balanced scorecard for sustainable supply chains: design and development guidelines. International Journal of Productivity and Performance Management, 62(8), 805-826. https://doi.org/10.1108/JJPPM-02-2013-0029

Schaltegger, S., \& Burritt,R. (2014). Measuring and Managing Sustainability Performance of Supply Chains: Review and Sustainability Supply Chain Management Framework. Supply Chain Management: An International Journal, 19(3), 232-241. https://doi.org/10.1108/SCM-02-2014-0061

Sekaran, U., \& Bougie, R. (2012). Research Methods for Business-A Skill Building Approach, $5^{\text {th }}$ ed. India: Wiley India (Pvt.) Ltd.

Seuring, S. (2011). Supply chain management for sustainable products - insights from research applying mixed methodologies. Business Strategy and Environment, 20(7), 471-484. https://doi.org/10.1002/bse.702

Seuring, S., \& Muller, M. (2008). From a literature review to a conceptual framework for sustainable supply chain management. Journal of Cleaner Production, 16(15), 1699-1710. https://doi.org/10.1016/j.jclepro.2008.04.020

Sloan, T. W. (2010). Measuring the Sustainability of Global Supply Chains: Current Practices and Future Directions. Journal of Global Business Management, 6(1), 1-16. Retrieved from http://www.jgbm.org

So, S., Parker, D., \& Xu, H. (2012). A conceptual framework for adopting sustainability in the supply chain. In: ANZAM operations, supply chain and services management symposium (pp. 397-413). ANZAM.

Starik, M., \& Rands, G. P. (1995). Weaving an integrated web: Multilevel and multisystem perspectives of ecologically sustainable organizations. Academy of Management Review, 20(4), 908-935. https://doi.org/10.5465/amr.1995.9512280025

Svensson, G. (2007). Aspects of sustainable supply chain management (SSCM): conceptual framework and empirical example. Supply chain management: An international journal, 12(4), 262-266. https://doi.org/10.1108/13598540710759781

Varsei, M., Soosay, C., Fahimnia,B., \& Sarkis, J. (2014). Framing Sustainability Performance of Supply Chains with Multidimensional Indicators. Supply Chain Management: An International Journal, 19(3), 242-257. https://doi.org/10.1108/SCM-12-2013-0436

Verdecho, M. J. L., Alfaro-Saiz, J. J., \& Rodriguez-Rodriguez, R. (2012). A Performance Measurement 
Framework for Monitoring Supply Chain Sustainability. Annals of Industrial Engineering, 331-338. Retrieved from https://link.springer.com

Walsh, J., Weber, K., \& Margolis, D. (2003). Social Issues and Management: Our Lost Cause Found. Journal of Management, 29(6), 859-881. https://doi.org/10.1016/S0149-2063(03)00082-5

Warhurst, A. (2002). Sustainability Indicators and Sustainability Performance Management, International Institute for Environment and Development, Mining Minerals and Sustainable Development, 43.

Winter, M., \& Knemeyer, A. M. (2013). Exploring the Integration of Sustainability and Supply Chain Management, Current state and Opportunities for Future Inquiry, International Journal of Physical Distribution and Logistics Management, 43(1), 18-38. https://doi.org/10.1108/09600031311293237

\section{Copyrights}

Copyright for this article is retained by the author(s), with first publication rights granted to the journal.

This is an open-access article distributed under the terms and conditions of the Creative Commons Attribution license (http://creativecommons.org/licenses/by/4.0/). 